\title{
Dietary patterns during pregnancy and risk of gestational diabetes: a prospective cohort study in Western China
}

\author{
Jonathan K. L. Mak', Ngoc Minh Pham,2, Andy H. Lee ${ }^{1}$, Li Tang ${ }^{3}$, Xiong-Fei Pan ${ }^{4}$, Colin W. Binns ${ }^{1}$ and Xin Sun ${ }^{3 *}$ (D)
}

\begin{abstract}
Background: Previous research has demonstrated the association between maternal dietary patterns and gestational diabetes (GDM), but evidence in Asian populations remains limited and inconsistent. This study investigated the association between dietary patterns during early pregnancy and the risk of GDM among pregnant women in Western China.
\end{abstract}

Methods: A prospective cohort study was conducted among 1337 pregnant women in Western China. Dietary intakes were assessed at 15-20 weeks of gestation using a validated food frequency questionnaire. GDM was diagnosed by oral glucose tolerance tests at 24-28 weeks of gestation. Exploratory factor analysis was performed to derive dietary patterns, and logistic regression models were used to examine the association between dietary patterns and GDM.

Results: A total of 199 women (14.9\%) developed GDM. Three dietary patterns were identified, namely, a plant-based pattern, a meat-based pattern and a high protein-low starch pattern. Notwithstanding a lack of association between dietary patterns and GDM risk in the whole cohort, there was a significant reduction in GDM risk among overweight women (BMI $\geq 24 \mathrm{~kg} / \mathrm{m}^{2}$ ); the odds ratio being 0.29 ( $95 \%$ confidence interval 0.09 to 0.94 ) when comparing the highest versus the lowest score of the high protein-low starch pattern.

Conclusions: There was no significant association between early pregnancy dietary patterns and GDM risk later in pregnancy for women in Western China, but high protein-low starch diet was associated with lower risk for GDM among women who were overweight at pre-pregnancy.

Keywords: China, Dietary patterns, Pregnancy, Body mass index, Gestational diabetes

\section{Background}

Gestational diabetes mellitus (GDM) is a common pregnancy complication in which women without diabetes develop glucose intolerance during pregnancy [1]. Global estimates of its prevalence vary from $<1$ to $28 \%$ contingent on diagnostic criteria and screening approaches used [2], but have risen by over $30 \%$ during the past two decades [3]. In Asia, the GDM prevalence is between $12 \%$ [3] and $14 \%$ [4], while in China, a recent meta-analysis has shown the total incidence of GDM was approximately 15\% [5]. GDM has been recognized as an underlying cause of maternal complications (e.g., pre-eclampsia, pregnancy-induced

\footnotetext{
* Correspondence: sunx79@hotmail.com

${ }^{3}$ Chinese Evidence-based Medicine Center, West China Hospital, Sichuan University, Chengdu 610041, China

Full list of author information is available at the end of the article
}

hypertension and caesarean section) and adverse infant outcomes such as macrosomia and preterm birth $[6,7]$. It also increases the risk of long-term metabolic conditions for both mother and offspring $[3,8]$.

Accumulating evidence has suggested that dietary intake before and during pregnancy is associated with the risk of GDM $[9,10]$. On one hand, high consumption of macronutrients (e.g., red meat, processed meat and eggs) and micronutrients (such as dietary heme iron, animal protein, total fat and cholesterol) can increase the GDM risk [1117]. On the other hand, increasing the intakes of fiber [18], nuts [14], and vegetable-derived protein [14, 15] may lower the GDM risk. Foods or nutrients are commonly consumed in combination rather than separately. As such, studying single food items may be unable to discern the relationship due to the interaction between macro- and 
micronutrients. Dietary pattern analysis, which represents a large and complex set of interrelated dietary factors, is a useful approach to evaluating the diet-GDM relationship. Prudent dietary patterns, such as vegetarian or Mediterranean-style diet, have been shown to reduce the risk of GDM [19]. Meanwhile, a Westernized or less healthy diet, characterized by high intakes of red and processed meat, refined grains and fried foods, is associated with increased risk of GDM [20-22]. Since dietary habits are different between racial and ethnic populations [23], it is of interest to examine the role of dietary patterns in the etiology of GDM, especially in Asia where there has been a rapid nutrition transition to a more Westernized diet [24], with increasing prevalence of GDM [3, 4].

Currently, studies of dietary patterns and GDM in Asia remain scarce with conflicting results. For instance, a study in Southern China showed a positive association between a seafood and sweets pattern and risk of GDM [25], whereas an inverse association was found for a seafood and noodle pattern and risk of GDM in a multi-ethnic Asian cohort [26]. It is unclear whether diet may impact the GDM burden, and whether there are regional differences in the association between dietary patterns and GDM risk. Given that GDM is strongly associated with pre-pregnancy body mass index (BMI) [27], its relationship with maternal dietary patterns may be modified by pregravid BMI levels [28]. The aim of this study was to investigate the association between dietary patterns during early pregnancy and the risk of GDM in Western China, taking into consideration the potential effect modification of pre-pregnancy BMI and other confounding factors.

\section{Methods}

\section{Study design and participants}

A prospective cohort study was conducted among pregnant women in Western China to identify modifiable risk factors (maternal lifestyle and nutritional status) of adverse pregnancy and infant health outcomes. Full details of the study protocol and recruitment procedures were described elsewhere [29]. Briefly, participants were recruited from four maternity hospitals in Chengdu, Sichuan Province. From May 2015 to August 2015, all pregnant women at 15 to 20 weeks of gestation who attended antenatal care at these hospitals were approached and assessed for eligibility. Eligible women were those aged 18-40 years, with singleton pregnancy, without severe chronic or infectious disease (e.g. HIV), and without any infertility treatment such as in vitro fertilization and intrauterine insemination. Only women who returned their signed consent form were included. In total, 1901 pregnant women were followed up from 15 to 20 weeks of gestation until 12 months postpartum. The study protocol was approved by the Ethics Committee of West China School of Public Health, Sichuan
University, and the Human Research Ethics Committee of Curtin University.

\section{Exposure assessment}

Dietary intake was assessed at baseline during 15-20 weeks of gestation via face-to-face interviews conducted by trained nurses, using a semi-quantitative Food Frequency Questionnaire (FFQ) originally developed for residents in Chongqing city (a municipality geographically adjacent to Sichuan province), Western China, with the exception of 10 items (four for oil and six for condiments) which are uncommon or deemed difficult to estimate [30]. The FFQ is based on a previous semi-quantitative FFQ validated among women in Chengdu, Sichuan province [31], with reported mean correlation coefficient of 22 nutrients and intra-class correlation coefficients being 0.66 and 0.65 , respectively. It contained 109 food and beverage items in 17 predefined groups, with quantities and frequencies recorded in detail. A standard portion (in grams) was defined for each food item listed. A photo booklet was available to show participants about the standard portion sizes, and they were asked to estimate their intake portion for each food, with the options of $0,0.5,0.8,1.0,1.5,2.0$ and 3.0 or above. They also chose their intake frequencies: $1-3$ times per month, 1-2 times per week, 3-4 times per week, 5-6 times per week, once per day, twice per day, three times per day, and four times or more per day. A daily food frequency intake was then computed. Total food intakes in grams per day were calculated using the product of daily frequency intake and amount of food intake per meal in standard portions. In addition, we adjusted food intakes for energy consumption using a density method by calculating the amount of food intake per $1000 \mathrm{kcal}$ of energy [32].

For the analysis of dietary patterns, 109 food and beverage items originally included in the FFQ were combined into 32 food and beverage groups based on their similarities in nutrient profile (see Appendix 1). Exploratory factor analysis with the principle component method [33] was applied to derive dietary patterns, based on the energy-adjusted intakes of food. Number of factors retained was determined by identifying a break point in the scree plot [34] and interpretability of patterns. Factors were rotated by orthogonal/varimax transformation to improve interpretability and utility. Dietary patterns were named according to the food items that contributed most to the pattern. We chose factor loadings $\geq 0.3$ to represent a high correlation between the food group and the dietary pattern. Accordingly, factor scores for each dietary pattern were calculated by the sum of food intake weighted by the corresponding factor loadings. 


\section{Outcome assessment}

GDM status was determined using oral glucose tolerance tests (OGTT). Between 24 and 28 weeks of gestation, participants who were not previously diagnosed as diabetic were routinely scheduled for a $75 \mathrm{~g}, 2$-h OGTT. Blood samples were collected at fasting, at 1 and $2 \mathrm{~h}$ after they received the $75 \mathrm{~g}$ oral glucose. GDM cases were confirmed using the IADPSG diagnostic criteria [35], including at least one of the following values being met: fasting serum glucose $\geq 5.1 \mathrm{mmol} / \mathrm{L}, 1$-h serum glucose $\geq 10.0 \mathrm{mmol} / \mathrm{L}$, or 2 -h post prandial serum glucose $\geq 8.5 \mathrm{mmol} / \mathrm{L}$.

\section{Assessment of covariates}

Information on socio-demographic and health characteristics, including maternal age, education, parity, family history of diabetes and cigarette smoking, was collected during the baseline survey. Maternal age was categorized into four groups $(<25,25-29,30-34, \geq 35$ years) for statistical analysis. Educational status was classified by three levels (junior secondary school or below, senior/technical secondary school, university or above). Physical activity during pregnancy was assessed using a validated Pregnancy Physical Activity Questionnaire [36] and expressed in terms of metabolic equivalent tasks (MET) [37]. Height was measured by a stadiometer, and self-reported pre-pregnancy weight was obtained from medical records. Pre-pregnancy body mass index (BMI) was then calculated as pre-pregnancy weight $(\mathrm{kg})$ divided by height squared $\left(\mathrm{m}^{2}\right)$. Participants with BMI $<18.5,18.5-23.9$ and $\geq 24 \mathrm{~kg} / \mathrm{m}^{2}$ were classified as underweight, normal and overweight, respectively [38].

\section{Statistical analysis}

Baseline characteristics were compared between groups using t-tests or analysis of variance (ANOVA) for continuous variables, and $\chi^{2}$ tests for categorical variables. Logistic regression models were used to ascertain the associations between different dietary patterns and risk of GDM, with the lowest tertile taken as the reference level. Crude and adjusted odds ratios (OR) together with 95\% confidence intervals (CI) were presented (see Appendix 2). Linear trend analysis was also performed for the logistic regressions. Potential covariates included age, pre-pregnancy BMI, family history of diabetes, parity, education and total physical activity. We examined potential effect modification by age groups, pre-pregnancy BMI $\left(<24 \mathrm{~kg} / \mathrm{m}^{2}\right.$, or $\left.\geq 24 \mathrm{~kg} / \mathrm{m}^{2}\right)$ and family history of diabetes (yes, no, or don't know) on the association between dietary patterns and GDM risk. We tested the significance of interaction by adding multiplicative interaction terms in the models. All statistical analyses were performed using Stata (version 14.2, Stata Corp, Texas, USA). A two-tailed $p$-value less than 0.05 was considered as statistically significant.

\section{Results}

Characteristics of participants

After excluding participants with a history of diabetes before pregnancy $(n=2)$, incomplete information on OGTT $(n=450)$ and those with missing data on diet $(n=112)$, 1337 women were available for analysis. No significant difference was observed between the included and excluded women in terms of age, pre-pregnancy BMI, education, parity, smoking habit and family history of diabetes.

Table 1 summarizes participant characteristics according to the GDM status. Overall, the mean age of participants was 25.8 years $(\mathrm{SD}=4.1)$, and women aged below 25 years accounted for $39.4 \%$ of the cohort. The mean pre-pregnancy BMI was $20.7 \mathrm{~kg} / \mathrm{m}^{2}(\mathrm{SD}=2.8)$, while the prevalence of overweight or obese (BMI $\geq 24 \mathrm{~kg} / \mathrm{m}^{2}$ ) was $12.6 \%$. In total, 199 women (14.9\%) were diagnosed with GDM, who tended to be older, had a higher pre-pregnancy BMI and a greater likelihood of family history of diabetes when compared to their non-GDM counterparts $(p<0.05)$.

\section{Dietary pattern analysis}

We identified three major dietary patterns that accounted for $21.2 \%$ of the total variation, with their rotated factor loadings presented in Table 2. The first pattern, named the 'plant-based pattern', was characterized by high intakes of green leafy vegetables, cruciferous vegetables, gourd/melon family vegetables, red or orange vegetables, potatoes, root vegetables, bean vegetables, bean products, mushrooms, fruits, and low intake of lean pork meat. It accounted for $9.0 \%$ of the total variance. The second pattern, called the 'meat-based pattern', was represented by high intakes of pork, pig blood curd, ox tripe, organ meat, processed meat, squid and mushrooms. It explained $7.1 \%$ of the total variance. The third pattern was typified by high intakes of foods rich in protein, including eggs, milk, fish and lean pork meat, and low intakes of noodles and bread. We named it the 'high protein-low starch pattern', which explained 5.0\% of the total variance.

Table 3 describes participants' characteristics and their dietary intakes according to tertiles of dietary pattern scores. For the plant-based pattern, women with a higher score were older, more highly educated and physically active than those with a lower score. They had higher intakes of total energy and lower intake of total fat. Also, they consumed more vegetables, fruit, nuts/seeds, fish, eggs, protein and carbohydrate, but less red meat. Regarding the meat-based pattern, women with a higher score were older and had more children than those with a lower score. They had higher intakes of total energy, vegetables, red meat, protein and total fat, but had lower intakes of fruit, nuts/seeds, milk, eggs, grains and carbohydrate. For the high protein-low starch pattern, women with a higher score were more educated and had a 
Table 1 Baseline characteristics of participants by prospective development of GDM ${ }^{\text {a }}$

\begin{tabular}{|c|c|c|c|c|}
\hline Characteristics & $\begin{array}{l}\text { Overall } \\
(n=1337)\end{array}$ & $\begin{array}{l}\text { GDM } \\
(n=199)\end{array}$ & $\begin{array}{l}\text { Non-GDM } \\
(n=1138)\end{array}$ & $p^{b}$ \\
\hline Age (year) & $25.8 \pm 4.1$ & $26.8 \pm 4.2$ & $25.7 \pm 4.0$ & $<0.001$ \\
\hline \multicolumn{4}{|l|}{ By category } & 0.002 \\
\hline$<25$ & $527(39.4)$ & $63(31.7)$ & $464(40.8)$ & \\
\hline $25-29$ & $589(44.1)$ & $86(43.2)$ & $503(44.2)$ & \\
\hline $30-34$ & $184(13.8)$ & $40(20.1)$ & $144(12.7)$ & \\
\hline$\geq 35$ & $37(2.8)$ & $10(5.0)$ & $27(2.4)$ & \\
\hline $\begin{array}{l}\text { Pre-pregnancy } \\
\text { BMI }\left(\mathrm{kg} / \mathrm{m}^{2}\right)\end{array}$ & $20.7 \pm 2.8$ & $21.8 \pm 3.2$ & $20.5 \pm 2.7$ & $<0.001$ \\
\hline \multicolumn{4}{|l|}{ By category } & $<0.001$ \\
\hline$<18.5$ & $304(22.7)$ & $28(14.1)$ & $276(24.3)$ & \\
\hline $18.5-23.9$ & $865(64.7)$ & $130(65.3)$ & $735(64.6)$ & \\
\hline$\geq 24$ & $168(12.6)$ & $41(20.6)$ & $127(11.2)$ & \\
\hline \multicolumn{4}{|l|}{$\begin{array}{l}\text { Family history of } \\
\text { diabetes }\end{array}$} & 0.006 \\
\hline Yes & $72(6.2)$ & $19(11.2)$ & $53(5.4)$ & \\
\hline No & $1013(87.5)$ & $136(80.5)$ & $877(88.7)$ & \\
\hline Don't know & $73(6.3)$ & $14(8.3)$ & $59(6.0)$ & \\
\hline \multicolumn{4}{|l|}{ Education } & 0.513 \\
\hline $\begin{array}{l}\text { Junior secondary } \\
\text { school or below }\end{array}$ & $321(24.0)$ & $51(25.6)$ & $270(23.7)$ & \\
\hline $\begin{array}{l}\text { Senior/technical } \\
\text { secondary school }\end{array}$ & $524(39.2)$ & $82(41.2)$ & $442(38.8)$ & \\
\hline University or above & $492(36.8)$ & $66(33.2)$ & $426(37.4)$ & \\
\hline \multicolumn{4}{|l|}{ Parity } & 0.747 \\
\hline 0 & $932(69.8)$ & $137(68.8)$ & $795(70.0)$ & \\
\hline$\geq 1$ & $403(30.2)$ & $62(31.2)$ & $341(30.0)$ & \\
\hline \multicolumn{4}{|l|}{$\begin{array}{l}\text { Active smoking } \\
\text { before pregnancy }\end{array}$} & 0.289 \\
\hline Yes & $73(5.5)$ & $14(7.0)$ & $59(5.2)$ & \\
\hline No & $1264(94.5)$ & $185(93.0)$ & 1079 (94.8) & \\
\hline $\begin{array}{l}\text { Total physical activity } \\
\text { (MET-hour/week) }\end{array}$ & $149.7 \pm 84.2$ & $145.4 \pm 82.6$ & $150.5 \pm 84.5$ & 0.439 \\
\hline
\end{tabular}

BMI body mass index, GDM gestational diabetes mellitus, MET Metabolic equivalent task

${ }^{a}$ Numbers are presented as $\mathrm{n}(\%)$ or mean \pm SD

based on t-tests or $x^{2}$ tests

lower pregravid BMI when compared to women with a lower score. Those with a higher versus lower score had higher total energy intake and higher consumption of fruit, nuts/seeds, red meat, lean pork, fish, milk, eggs, protein and total fat, while their intake of vegetables, grains, and carbohydrate was lower.

\section{Dietary patterns and risk of gestational diabetes}

There was no significant association between any dietary pattern and the risk of GDM. Compared with the lowest tertile of dietary pattern scores, multivariable-adjusted ORs for the corresponding highest tertile for the plant-based, meat-based and high protein-low starch patterns were $0.97(95 \% \mathrm{CI}$ 0.64 to $1.47, p>0.05$ ), 0.89 (95\% CI 0.58 to $1.36, p>$ 0.05 ) and 0.73 (95\% CI 0.48 to $1.10, p>0.05)$, respectively (Appendix 2).

In subgroup analyses, a significant reduction in GDM risk was observed among overweight women, when comparing the highest tertile of high protein-low starch pattern scores to the lowest tertile (OR $0.29 ; 95 \%$ CI 0.09 to $0.94 ; p$ for trend $=0.049$, Figure 1), despite the lack of significance for the interaction between pre-pregnancy BMI and high protein-low starch pattern score $(p$ for interaction $=$ $0.134)$. There was no effect modification by pregravid BMI on the association between the plant-based pattern and meat-based pattern and GDM risk. Neither age nor family history of diabetes modified the risk of GDM in relation to the identified dietary patterns (data not shown for brevity).

\section{Discussion}

In the present prospective cohort study of 1337 pregnant women in Western China, three dietary patterns called the plant-based pattern, meat-based pattern and high protein-low starch pattern were identified. Despite the lack of association between the three dietary patterns and the risk of GDM in the whole cohort, we observed a significant inverse association between the high protein-low starch pattern and risk of GDM only among overweight women. Our finding suggested that increasing the intake of high protein-low starch foods during early pregnancy may be beneficial towards the prevention of GDM for overweight or obese women at pre-pregnancy.

Unlike prior research [11], the present study found no significant association between the identified dietary patterns and the risk of GDM in all participants. One possible reason may be due to the different dietary patterns derived in different studies. Dietary pattern analysis is a holistic approach to determining the role of combinations of foods and nutrients consumed in cardiometabolic health including GDM [39]. However, results remain inconsistent due to the heterogeneity of diet composition across the world regions [23]. Similarly, within-country differences in dietary patterns exist. In China, for example, Southern Chinese eat rice as the staple food, unlike their northern counterparts who eat bread and buns regularly [40], which may contribute to the inconsistency regarding the association between dietary patterns and GDM risk in Chinese mothers [25, 41].

An alternative explanation is our study participants had fewer risk factor clusters in addition to GDM than those in previous studies. According to a population-based study 
Table 2 Rotated factor loadings of the three major dietary patterns ${ }^{a}$

\begin{tabular}{|c|c|c|c|}
\hline Food groups & Plant-based pattern & Meat-based pattern & High protein-low starch pattern \\
\hline Green leafy vegetables & 0.65 & 0.26 & 0.06 \\
\hline Root vegetables & 0.56 & 0.15 & 0.04 \\
\hline Gourd/melon family vegetables & 0.55 & -0.05 & -0.07 \\
\hline Red/orange vegetables & 0.51 & -0.15 & -0.01 \\
\hline Cruciferous vegetables & 0.48 & 0.11 & 0.08 \\
\hline Bean vegetables & 0.41 & 0.00 & -0.20 \\
\hline Potatoes & 0.40 & -0.02 & -0.21 \\
\hline Mushrooms & 0.39 & 0.39 & 0.11 \\
\hline Bean products & 0.35 & -0.01 & -0.06 \\
\hline Fruits & 0.31 & -0.12 & 0.18 \\
\hline Organ meat & 0.13 & 0.67 & -0.01 \\
\hline Ox tripe & -0.05 & 0.59 & -0.06 \\
\hline Pig blood curd & 0.10 & 0.50 & 0.00 \\
\hline Squid & 0.03 & 0.45 & -0.04 \\
\hline Pork & 0.16 & 0.39 & 0.24 \\
\hline Processed meat & 0.01 & 0.37 & -0.19 \\
\hline Eggs & 0.02 & -0.12 & 0.48 \\
\hline Milk & 0.03 & -0.24 & 0.40 \\
\hline Lean pork meat & -0.34 & 0.10 & 0.40 \\
\hline Fish & 0.27 & 0.22 & 0.40 \\
\hline Noodles & -0.01 & 0.04 & -0.44 \\
\hline Bread & 0.11 & -0.01 & -0.43 \\
\hline Sea vegetables & 0.26 & 0.27 & 0.11 \\
\hline Pickled vegetables & 0.11 & 0.07 & -0.13 \\
\hline Nuts and seeds & 0.28 & -0.12 & 0.28 \\
\hline Beef & 0.23 & 0.27 & 0.03 \\
\hline Poultry & 0.26 & 0.26 & 0.26 \\
\hline Processed eggs & -0.09 & 0.23 & 0.15 \\
\hline Rice & -0.28 & -0.18 & -0.24 \\
\hline Maize & 0.21 & -0.08 & -0.07 \\
\hline Alcohol & -0.03 & 0.04 & -0.10 \\
\hline Coffee/Tea & -0.02 & 0.01 & -0.05 \\
\hline Variance explained (\%) & 9.04 & 7.10 & 5.01 \\
\hline
\end{tabular}

${ }^{\mathrm{a}}$ Factor loadings $\geq \pm 0.30$ are bolded

of 98,271 adults in Western China [42], the prevalence of overweight or obese (BMI $\geq 24 \mathrm{~kg} / \mathrm{m}^{2}$ ) was much higher than our cohort (28.0\% versus $12.6 \%$ ). Moreover, our participants were younger (mean age 25.8 years) than those (28.9 and 28.0 years) of two previous studies in China [25, 41]. The effect of dietary patterns, if any, on the risk of GDM may not be discernible among women with an apparently low risk profile of developing GDM in the present study.

An inverse association was found between the consumption of high protein-low starch foods and the risk of GDM among overweight Chinese women. This dietary pattern was characterized by a high intake of eggs, milk, fish and lean pork, as well as a low intake of starchy carbohydrates. The apparent reduction in GDM risk may be partly due to the antidiabetic effects of milk [43] and fish [44]. Overweight/obesity is associated with insulin resistance [45], impaired insulin section [46] and elevated inflammation levels [47]. A major protein in milk, whey proteins [48, 49], has been demonstrated to increase insulin sensitivity [50], regulate blood glucose levels and decrease low-grade inflammation, oxidative stress as well as body weight [51]. In 
Table 3 Baseline characteristics and dietary intakes of participants by tertiles of dietary pattern scores ${ }^{a}$

\begin{tabular}{|c|c|c|c|c|c|c|c|c|c|}
\hline \multirow[t]{2}{*}{ Variable } & \multicolumn{3}{|c|}{ Plant-based pattern } & \multicolumn{3}{|c|}{ Meat-based pattern } & \multicolumn{3}{|c|}{ High protein-low starch pattern } \\
\hline & Tertile 1 & Tertile 3 & $p^{b}$ & Tertile 1 & Tertile 3 & $p^{b}$ & Tertile 1 & Tertile 3 & $p^{b}$ \\
\hline Age (year), mean $\pm S D$ & $25.5 \pm 3.9$ & $26.1 \pm 4.1$ & 0.053 & $25.4 \pm 4.0$ & $26.1 \pm 4.2$ & 0.034 & $25.8 \pm 4.1$ & $25.9 \pm 4.3$ & 0.830 \\
\hline Pre-pregnancy BMI (kg/m²) & & & 0.701 & & & 0.518 & & & 0.047 \\
\hline$<18.5$ & $109(24.4)$ & $97(21.8)$ & & $104(23.3)$ & $95(21.4)$ & & $96(21.5)$ & $97(21.8)$ & \\
\hline $18.5-23.9$ & $278(62.3)$ & $290(65.2)$ & & $279(62.6)$ & $301(67.6)$ & & $284(63.7)$ & $307(69.0)$ & \\
\hline$\geq 24$ & $59(13.2)$ & $58(13.0)$ & & $63(14.1)$ & $49(11.0)$ & & $66(14.8)$ & $41(9.2)$ & \\
\hline Family history of diabetes & $24(6.1)$ & $28(7.4)$ & 0.677 & $24(6.4)$ & $18(4.7)$ & 0.360 & $23(5.9)$ & $27(7.1)$ & 0.454 \\
\hline Education & & & 0.011 & & & 0.184 & & & 0.024 \\
\hline Junior secondary school or below & $132(29.6)$ & $93(20.9)$ & & $105(23.5)$ & $117(26.3)$ & & $121(27.1)$ & $103(23.2)$ & \\
\hline $\begin{array}{l}\text { Senior/technical secondary } \\
\text { school }\end{array}$ & $163(36.6)$ & $173(38.9)$ & & $189(42.4)$ & $156(35.1)$ & & $186(41.7)$ & $175(39.3)$ & \\
\hline University or above & $151(33.9)$ & $179(40.2)$ & & $152(34.1)$ & $172(38.7)$ & & $139(31.2)$ & $167(37.5)$ & \\
\hline Parity & & & 0.293 & & & $<0.001$ & & & 0.037 \\
\hline 0 & $299(67.0)$ & $316(71.0)$ & & $338(75.8)$ & $285(64.0)$ & & $292(65.5)$ & $325(73.2)$ & \\
\hline$\geq 1$ & $147(33.0)$ & $129(29.0)$ & & $108(24.2)$ & $160(36.0)$ & & $154(34.5)$ & $119(26.8)$ & \\
\hline \multicolumn{10}{|l|}{ Active smoking before pregnancy } \\
\hline Yes & $26(5.8)$ & $18(4.0)$ & 0.249 & $23(5.2)$ & $30(6.7)$ & 0.314 & $29(6.5)$ & $25(5.6)$ & 0.332 \\
\hline No & $420(94.2)$ & $427(96.0)$ & & $423(94.8)$ & $415(93.3)$ & & $417(93.5)$ & $420(94.4)$ & \\
\hline $\begin{array}{l}\text { Total physical activity (MET-hour/ } \\
\text { week) }\end{array}$ & $141.1 \pm 81.1$ & $157.7 \pm 87.7$ & 0.013 & $144.3 \pm 83.9$ & $156.7 \pm 85.2$ & 0.082 & $146.2 \pm 80.3$ & $149.9 \pm 86.1$ & 0.468 \\
\hline $\begin{array}{l}\text { Total energy consumption } \\
\text { (kcal/day) }\end{array}$ & $\begin{array}{l}1757.2 \pm \\
775.7\end{array}$ & $\begin{array}{l}2026.3 \pm \\
855.5\end{array}$ & $<0.001$ & $\begin{array}{l}1709.0 \pm \\
569.8\end{array}$ & $\begin{array}{l}2045.1 \pm \\
956.7\end{array}$ & $<0.001$ & $\begin{array}{l}1736.7 \pm \\
770.0\end{array}$ & $\begin{array}{l}2017.1 \pm \\
814.7\end{array}$ & $<0.001$ \\
\hline \multicolumn{10}{|l|}{$\begin{array}{l}\text { Energy-adjusted food intake } \\
\text { (g/1000 kcal/day) }\end{array}$} \\
\hline$V$ egetables ${ }^{c}$ & $85.9 \pm 34.1$ & $\begin{array}{l}256.1 \pm \\
104.7\end{array}$ & $<0.001$ & $\begin{array}{l}165.6 \pm \\
110.4\end{array}$ & $171.7 \pm 99.8$ & $<0.001$ & $164.3 \pm 96.7$ & $160.9 \pm 98.9$ & 0.787 \\
\hline Fruits & $65.4 \pm 61.0$ & $131.5 \pm 97.6$ & $<0.001$ & $\begin{array}{l}120.3 \pm \\
102.8\end{array}$ & $81.9 \pm 66.9$ & $<0.001$ & $80.6 \pm 69.8$ & $\begin{array}{l}115.4 \pm \\
101.0\end{array}$ & $<0.001$ \\
\hline Nuts and seeds & $7.6 \pm 7.4$ & $15.1 \pm 13.3$ & $<0.001$ & $14.0 \pm 13.6$ & $10.2 \pm 9.2$ & $<0.001$ & $8.2 \pm 7.7$ & $15.4 \pm 13.8$ & $<0.001$ \\
\hline Red meat $^{d}$ & $51.2 \pm 31.2$ & $37.1 \pm 24.2$ & $<0.001$ & $28.3 \pm 22.0$ & $56.1 \pm 28.4$ & $<0.001$ & $31.4 \pm 23.0$ & $52.6 \pm 30.5$ & $<0.001$ \\
\hline Lean pork meat & $34.5 \pm 26.6$ & $23.4 \pm 18.5$ & $<0.001$ & $24.5 \pm 22.2$ & $33.2 \pm 25.1$ & $<0.001$ & $19.9 \pm 18.2$ & $38.1 \pm 26.3$ & $<0.001$ \\
\hline Fish & $10.3 \pm 9.9$ & $19.3 \pm 20.2$ & $<0.001$ & $11.0 \pm 15.1$ & $19.4 \pm 20.0$ & $<0.001$ & $9.1 \pm 8.7$ & $21.2 \pm 23.5$ & $<0.001$ \\
\hline Milk & $89.2 \pm 85.9$ & $96.1 \pm 77.4$ & 0.002 & $\begin{array}{l}127.8 \pm \\
101.2\end{array}$ & $76.0 \pm 66.4$ & $<0.001$ & $60.7 \pm 60.2$ & $136.0 \pm 98.7$ & $<0.001$ \\
\hline Eggs & $18.4 \pm 18.8$ & $19.9 \pm 13.9$ & 0.015 & $23.7 \pm 19.8$ & $18.1 \pm 16.5$ & $<0.001$ & $11.5 \pm 11.5$ & $29.1 \pm 20.7$ & $<0.001$ \\
\hline Grains $^{e}$ & $203.3 \pm 70.5$ & $173.1 \pm 54.7$ & $<0.001$ & $199.6 \pm 61.9$ & $171.1 \pm 61.2$ & $<0.001$ & $224.3 \pm 61.1$ & $147.1 \pm 46.9$ & $<0.001$ \\
\hline \multicolumn{10}{|l|}{ Nutrient intake (\% energy) } \\
\hline Protein & $13.4 \pm 2.8$ & $14.6 \pm 2.4$ & $<0.001$ & $13.3 \pm 2.5$ & $14.9 \pm 2.7$ & $<0.001$ & $12.3 \pm 2.2$ & $15.7 \pm 2.4$ & $<0.001$ \\
\hline Total fat & $50.4 \pm 7.6$ & $43.8 \pm 6.8$ & $<0.001$ & $45.7 \pm 7.5$ & $48.4 \pm 8.5$ & $<0.001$ & $42.5 \pm 7.4$ & $51.3 \pm 6.8$ & $<0.001$ \\
\hline Carbohydrate & $37.1 \pm 8.8$ & $43.6 \pm 7.3$ & $<0.001$ & $42.6 \pm 8.2$ & $38.0 \pm 9.0$ & $<0.001$ & $46.7 \pm 7.3$ & $34.3 \pm 7.2$ & $<0.001$ \\
\hline
\end{tabular}

BMI body mass index, MET Metabolic equivalent task

${ }^{a}$ Numbers are presented as $n(\%)$ or mean \pm SD. Tertile 2 are not presented for brevity

${ }^{b}$ Based on ANOVA or $x^{2}$ tests

'Included green leafy vegetables, cruciferous vegetables, gourd/melon family vegetables, red/orange vegetables, root vegetables, bean vegetables and mushrooms

${ }^{\mathrm{d}}$ Included pork, beef, ox tripe, pig blood curd, processed meat and organ meat

encluded rice, noodles, bread and maize 


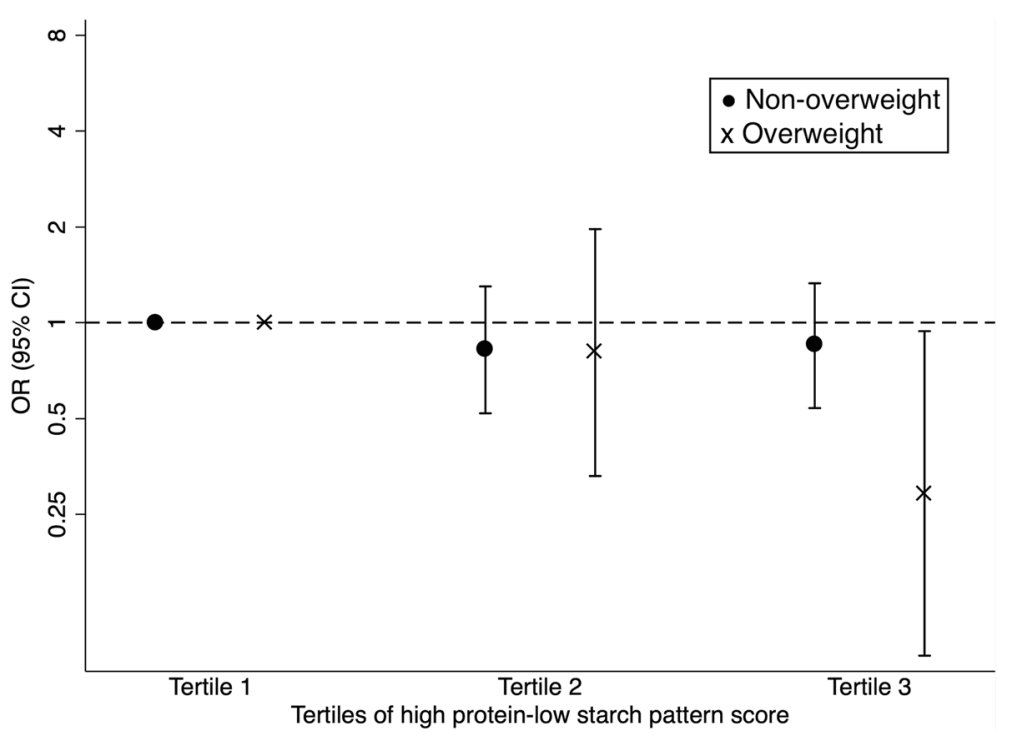

Fig. 1 Association between the high protein-low starch pattern and gestational diabetes according to pre-pregnancy body mass index levels. The model is adjusted for age, family history of diabetes, education, parity and total physical activity. Circle (•) represents women with BMl $<24 \mathrm{~kg} / \mathrm{m}^{2}$; $\operatorname{cross}(x)$ denotes women with $\mathrm{BMl} \geq 24 \mathrm{~kg} / \mathrm{m}^{2}$

addition, fatty acids in fish possess anti-inflammatory properties [52], while egg-derived phospholipids [53] can elevate high-density lipoproteins [54], which have been suggested to control glucose homeostasis [55]. Besides the potent anti-oxidative and anti-inflammatory properties of egg lutein and zeaxanthin [56], egg whites may have insulin-sensitizing effects [57]. Another possibility is that adherence to the high protein-low starch pattern can lead to greater weight loss in overweight individuals [58], while a high body weight is an established risk factor for GDM. Finally, a lower intake of starchy carbohydrates (e.g., noodles and bread) may reduce the risk of GDM through improved insulin resistance and insulin sensitivity as well as regulation of blood glucose levels $[59,60]$.

A major strength of this study is our cohort design, in which information on dietary intake was obtained during early pregnancy before the diagnosis of GDM. This allows assessment of the temporal relationship between dietary patterns and risk of developing GDM. In addition, dietary data were collected via direct interviews using a validated and reliable FFQ, and GDM was determined through OGTT to minimize potential exposure measurement errors and misclassification of the outcome, respectively. The analysis of dietary patterns, instead of separate food items or nutrients, enables the description of overall diet of pregnant women by accounting for interactions between food groups and/or nutrients. Indeed, a dietary pattern is amenable to interpretation by the general public and provides a base for development of dietary guidelines [61].

Several limitations should be considered. Firstly, the use of exploratory factor analysis with the principal component method requires some arbitrary decisions to include variables, the number of retained factors, the method of rotation and labelling of the factors [33]. This approach may limit the generalizability of our results. Secondly, habitual dietary intakes may not be fully captured by the FFQ which is limited by its pre-coded food items [62]. The level of accuracy in individual portion size estimation is another issue because Chinese adults normally eat communally and share their dishes with others [40]. Thirdly, dietary intake was assessed at a single time point, even though the habitual diet of pregnant women may change over time [63]. Finally, despite the adjustment for plausible factors associated with diet and GDM in the logistic regression models, residual confounding cannot be ruled out.

\section{Conclusion}

This is the first study in Western China to investigate the prospective association between dietary patterns during early pregnancy and the risk of GDM. Three major dietary patterns were identified among Western Chinese women: plant-based, meat-based and high protein-low starch pattern. Overall, our study indicated a lack of association between dietary patterns and the GDM risk. However, there was a significant inverse association between the high protein-low starch pattern characterized by high intake of milk, eggs, fish and lean meat and low intake of starch, and the incidence of GDM for Chinese women who were overweight at pre-pregnancy. Further research is needed to elucidate the role of diet in the prevention of GDM in China. 


\section{Appendix 1}

Table 4 Food groups used in dietary pattern analysis

\begin{tabular}{|c|c|c|}
\hline$\#$ & Food group & Food items \\
\hline 1 & Green leafy vegetables & $\begin{array}{l}\text { Lettuce leaves, lettuce head, Chinese mallow, Swiss chard, young garlic shoot, celery, pak choi, Houttuynia } \\
\text { cordata, flower Chinese cabbage, pea seedlings, spinach, garlic bolt, water spinach, bamboo shoots, green } \\
\text { Chinese onion, Chinese toon, Chinese chives, caraway }\end{array}$ \\
\hline 2 & Cruciferous vegetables & Cabbage, cauliflower \\
\hline 3 & Gourd/melon family vegetables & Cucumber, eggplant, bitter gourd, green chilies, towel gourd \\
\hline 4 & Red/orange vegetables & Carrot, pumpkin, tomato \\
\hline 5 & Potatoes & Potato \\
\hline 6 & Root vegetables & Lotus root, sweet potato, white radish, garlic \\
\hline 7 & Bean vegetables & Broad bean, soybean, soybean sprouts, green bean, mung bean sprouts, string bean, pea \\
\hline 8 & Bean products & Tofu, dried tofu, soybean milk, bean curd jelly, Chinese vermicelli, Chinese jelly noodles \\
\hline 9 & Mushrooms & Mushroom, black fungus, oyster mushroom, needle mushroom, white fungus \\
\hline 10 & Sea vegetables & Seaweed, sea lettuce \\
\hline 11 & Pickled vegetables & Pickled Chinese cabbage, pickled garlic, pickled radish, preserved Szechuan pickle \\
\hline 12 & Fruits & Apple, orange, banana, pear \\
\hline 13 & Nuts and seeds & Peanut, walnut, sesame, sunflower seed \\
\hline 14 & Pork & Pork, pork ribs, pork fat, trotters \\
\hline 15 & Pig blood curd & Pig blood curd \\
\hline 16 & Lean pork meat & Lean pork \\
\hline 17 & Beef & Beef \\
\hline 18 & Ox tripe & Ox tripe \\
\hline 19 & Organ meat & Pork liver, pig kidney, pork intestine, duck gizzard, duck intestine \\
\hline 20 & Poultry & Chicken, duck, goose \\
\hline 21 & Processed meat & Sausage, preserved meat \\
\hline 22 & Fish & Silver carp, crucian, grass carp, eel, hair tail \\
\hline 23 & Squid & Squid \\
\hline 24 & Milk & Milk \\
\hline 25 & Eggs & Egg, duck egg \\
\hline 26 & Processed eggs & Preserved egg, salted duck egg \\
\hline 27 & Rice & Polished round-grained rice, glutinous rice, rice noodles \\
\hline 28 & Noodles & Noodles, instant noodles \\
\hline 29 & Bread & Bread, steamed bun, steamed twisted roll, flour \\
\hline 30 & Maize & Corn, maize flour \\
\hline 31 & Alcohol & Beer, Chinese liquor \\
\hline 32 & Coffee/Tea & Coffee, tea \\
\hline
\end{tabular}




\section{Appendix 2}

Table $\mathbf{5}$ Odds ratios (95\% confidence interval) for gestational diabetes mellitus (GDM) according to dietary pattern scores

\begin{tabular}{|c|c|c|c|c|}
\hline Dietary patterns & Tertile 1 & Tertile 2 & Tertile 3 & $p$-trenc \\
\hline \multicolumn{5}{|l|}{ Plant-based pattern } \\
\hline GDM cases / pregnancies & $63 / 446$ & $64 / 446$ & $72 / 445$ & \\
\hline Model $1^{\mathrm{a}}$ & 1.00 & $1.02(0.70,1.48)$ & $1.17(0.81,1.69)$ & 0.367 \\
\hline Model $2^{\mathrm{b}}$ & 1.00 & $0.95(0.63,1.43)$ & $0.97(0.65,1.46)$ & 0.919 \\
\hline Model $3^{c}$ & 1.00 & $0.94(0.62,1.42)$ & $0.97(0.64,1.47)$ & 0.915 \\
\hline \multicolumn{5}{|l|}{ Meat-based pattern } \\
\hline GDM case/pregnancies & $65 / 446$ & $73 / 446$ & $61 / 445$ & \\
\hline Model $1^{\text {a }}$ & 1.00 & $1.15(0.80,1.65)$ & $0.93(0.64,1.36)$ & 0.628 \\
\hline Model $2^{b}$ & 1.00 & $1.05(0.70,1.57)$ & $0.82(0.54,1.25)$ & 0.318 \\
\hline Model $3^{c}$ & 1.00 & $1.08(0.72,1.62)$ & $0.89(0.58,1.36)$ & 0.534 \\
\hline \multicolumn{5}{|l|}{ High protein-low starch pattern } \\
\hline GDM case/pregnancies & $77 / 446$ & $60 / 446$ & $62 / 445$ & \\
\hline Model $1^{\mathrm{a}}$ & 1.00 & $0.74(0.52,1.07)$ & $0.78(0.54,1.12)$ & 0.148 \\
\hline Model $2^{b}$ & 1.00 & $0.83(0.56,1.23)$ & $0.73(0.49,1.11)$ & 0.137 \\
\hline Model $3^{c}$ & 1.00 & $0.84(0.56,1.26)$ & $0.73(0.48,1.10)$ & 0.132 \\
\hline
\end{tabular}

${ }^{\text {aCrude model }}$

${ }^{\mathrm{b}}$ Adjusted for age, pre-pregnancy body mass index and family history of diabetes

${ }^{\mathrm{c} A d d i t i o n a l l y ~ a d j u s t e d ~ f o r ~ p a r i t y, ~ e d u c a t i o n ~ a n d ~ t o t a l ~ p h y s i c a l ~ a c t i v i t y ~}$

\section{Abbreviations}

ANOVA: Analysis of variance; BMI: Body mass index; Cl: Confidence interval; FFQ: Food frequency questionnaire; GDM: Gestational diabetes mellitus; IADPSG: International Association of Diabetes and Pregnancy Study Groups; MET: Metabolic equivalent task; OGTT: Oral glucose tolerance test; OR: Odds ratio; SD: Standard deviation

\section{Acknowledgements}

The authors would like to thank all the participants, health professionals and researchers who contributed to this cohort study.

\section{Funding}

This study was supported by the China Medical Board (Grant No. 14-199).

\section{Availability of data and materials}

The datasets used and/or analyzed during the current study are available from the corresponding author upon request.

\section{Authors' contributions}

$A H L, C W B$ and XS designed the research protocol; LT and XFP conducted the study; JKLM and NMP analyzed the data; JKLM drafted the manuscript; $A H L, N M P$ and CWB critically revised the manuscript, and XS was responsible for the final contents. All authors read and approved the final manuscript.

\section{Ethics approval and consent to participate}

This study was approved by the ethics committee of West China School of Public Health, Sichuan University and the Human Research Ethics Committee of Curtin University. All participants have signed a consent form before enrollment to the study.

\section{Consent for publication}

Not applicable.

\section{Competing interests}

The authors declare that they have no competing interests.

\section{Publisher's Note}

Springer Nature remains neutral with regard to jurisdictional claims in published maps and institutional affiliations.

\section{Author details}

${ }^{1}$ School of Public Health, Curtin University, Perth, WA, Australia. ${ }^{2}$ Thai Nguyen University of Medicine and Pharmacy, Thai Nguyen, Vietnam. ${ }^{3}$ Chinese Evidence-based Medicine Center, West China Hospital, Sichuan University, Chengdu 610041, China. ${ }^{4}$ Department of Epidemiology and Biostatistics, School of Public Health, Tongji Medical College, Huazhong University of Science and Technology, Wuhan, China.

Received: 1 June 2018 Accepted: 28 October 2018

Published online: 20 November 2018

\section{References}

1. American Diabetes Association. Gestational diabetes mellitus. Diabetes Care. 2004;27(Suppl 1):S88-90

2. Jiwani A, Marseille E, Lohse N, Damm P, Hod M, Kahn JG. Gestational diabetes mellitus: results from a survey of country prevalence and practices. Matern Neonatal Med. 2012;25:600-10.

3. Zhu Y, Zhang C. Prevalence of gestational diabetes and risk of progression to type 2 diabetes: a global perspective. Curr Diab Rep. 2016;16:7.

4. Nguyen $\mathrm{CL}$, Pham NM, Binns CW, Duong DV, Lee AH. Prevalence of gestational diabetes mellitus in eastern and southeastern Asia: a systematic review and meta-analysis. J Diabetes Res. 2018;2018:1-10.

5. Gao C, Sun X, Lu L, Liu F, Yuan J. Prevalence of gestational diabetes mellitus in mainland China: a systematic review and meta-analysis. J Diabetes Investig. 2018. https://doi.org/10.1111/jdi.12854.

6. Wendland EM, Torloni MR, Falavigna M, Trujillo J, Dode MA, Campos MA, et al. Gestational diabetes and pregnancy outcomes - a systematic review of the World Health Organization (WHO) and the International Association of Diabetes in Pregnancy Study Groups (IADPSG) diagnostic criteria. BMC Pregnancy Childbirth. 2012;12:23. 
7. Billionnet C, Mitanchez D, Weill A, Nizard J, Alla F, Hartemann A, et al. Gestational diabetes and adverse perinatal outcomes from 716,152 births in France in 2012. Diabetologia. 2017;60:636-44.

8. Damm P, Houshmand-Oeregaard A, Kelstrup L, Lauenborg J, Mathiesen ER, Clausen TD. Gestational diabetes mellitus and long-term consequences for mother and offspring: a view from Denmark. Diabetologia. 2016;59:1396-9.

9. Zhang C, Ning Y. Effect of dietary and lifestyle factors on the risk of gestational diabetes: review of epidemiologic evidence. Am J Clin Nutr. 2011;94:1975S-9S

10. Schoenaker DAJM, Mishra GD, Callaway LK, Soedamah-Muthu SS. The role of energy, nutrients, foods, and dietary patterns in the development of gestational diabetes mellitus: a systematic review of observational studies. Diabetes Care. 2016:39:16-23.

11. Zhang C, Schulze MB, Solomon CG, Hu FB. A prospective study of dietary patterns, meat intake and the risk of gestational diabetes mellitus. Diabetologia. 2006;49:2604-13.

12. Qiu C, Frederick IO, Zhang C, Sorensen TK, Enquobahrie DA, Williams MA. Risk of gestational diabetes mellitus in relation to maternal egg and cholesterol intake. Am J Epidemiol. 2011:173:649-58.

13. Bowers K, Yeung E, Williams MA, Qi L, Tobias DK, Hu FB, et al. A prospective study of prepregnancy dietary iron intake and risk for gestational diabetes mellitus. Diabetes Care. 2011;34:1557-63.

14. Bao W, Bowers K, Tobias DK, Hu FB, Zhang C. Prepregnancy dietary protein intake, major dietary protein sources, and the risk of gestational diabetes mellitus: a prospective cohort study. Diabetes Care. 2013;36:2001-8.

15. Bao W, Bowers K, Tobias DK, Olsen SF, Chavarro J, Vaag A, et al. Prepregnancy low-carbohydrate dietary pattern and risk of gestational diabetes mellitus: a prospective cohort study. Am J Clin Nutr. 2014;99:1378-84

16. Bo S, Menato G, Lezo A, Signorile A, Bardelli C, DeMichieli F, et al. Dietary fat and gestational hyperglycaemia. Diabetologia. 2001;44:972-8.

17. Bowers K, Tobias DK, Yeung E, Hu FB, Zhang C. A prospective study of prepregnancy dietary fat intake and risk of gestational diabetes. Am J Clin Nutr. 2012;95:446-53.

18. Zhang C, Liu S, Solomon CG, Hu FB. Dietary fiber intake, dietary glycemic load, and the risk for gestational diabetes mellitus. Diabetes Care. 2006;29:2223-30.

19. Pham NM, Do V. Van, lee AH. Polyphenol-rich foods and risk of gestational diabetes: a systematic review and meta-analysis. Eur J Clin Nutr. https://doi. org/10.1038/s41430-018-0218-7.

20. Shin D, Lee K, Song W. Dietary patterns during pregnancy are associated with risk of gestational diabetes mellitus. Nutrients. 2015;7:9369-82.

21. Schoenaker DAJM, Soedamah-Muthu SS, Callaway LK, Mishra GD. Prepregnancy dietary patterns and risk of gestational diabetes mellitus: results from an Australian population-based prospective cohort study. Diabetologia. 2015;58:2726-35.

22. Donazar-Ezcurra M, Lopez-Del Burgo C, Martinez-Gonzalez MA, BasterraGortari FJ, de Irala J, Bes-Rastrollo M. Pre-pregnancy adherences to empirically derived dietary patterns and gestational diabetes risk in a Mediterranean cohort: the Seguimiento Universidad de Navarra (SUN) project. Br J Nutr. 2017;118:715-21.

23. Imamura F, Micha R, Khatibzadeh S, Fahimi S, Shi P, Powles J, et al. Dietary quality among men and women in 187 countries in 1990 and 2010: a systematic assessment. Lancet Glob Health. 2015;3:e132-42.

24. Kelly $M$. The nutrition transition in developing asia: dietary change, drivers and health impacts. In: Jackson P, Spiess WEL, Sultana F, editors. Eating, Drinking: Surviving. Cham: Springer; 2016. p. 83-90.

25. He J-R, Yuan M-Y, Chen N-N, Lu J-H, Hu C-Y, Mai W-B, et al. Maternal dietary patterns and gestational diabetes mellitus: a large prospective cohort study in China. Br J Nutr. 2015;113:1292-300

26. de Seymour J, Chia A, Colega M, Jones B, McKenzie E, Shirong C, et al. Maternal dietary patterns and gestational diabetes mellitus in a multi-ethnic asian cohort: the GUSTO study. Nutrients. 2016;8:574.

27. Ogonowski J, Miazgowski T, Kuczynska M, Krzyzanowska-Swiniarska B, Celewicz Z. Pregravid body mass index as a predictor of gestational diabetes mellitus. Diabet Med. 2009:26:334-8.

28. Tryggvadottir EA, Medek H, Birgisdottir BE, Geirsson RT, Gunnarsdottir I. Association between healthy maternal dietary pattern and risk for gestational diabetes mellitus. Eur J Clin Nutr. 2016;70:237-42.

29. Tang L, Pan X-F, Lee AH, Binns CW, Yang C-X, Sun X. Maternal lifestyle and nutritional status in relation to pregnancy and infant health outcomes in Western China: protocol for a prospective cohort study. BMJ Open. 2017;7:e014874.
30. Zhou Z-Y, Takezaki T, Mo B-Q, Sun H-M, Wang W-C, Sun L-P, et al. Development of a semi-quantitative food frequency questionnaire to determine variation in nutrient intakes between urban and rural areas of Chongqing, China. Asia Pac J Clin Nutr. 2004;13:273-83.

31. Tang Y, Liu Y, Xu L, Jia Y, Shan D, Li W, et al. Validity and reproducibility of a revised semi-quantitative food frequency questionnaire (SQFFQ) for women of age-group 12-44 years in Chengdu. J Health Popul Nutr. 2015;33:50-9.

32. Willett WC, Howe GR, Kushi LH. Adjustment for total energy intake in epidemiologic studies. Am J Clin Nutr. 1997;65:1220S-8S discussion 1229S-1231S

33. Rencher AC, Christensen WF. Exploratory factor analysis. In: Methods of multivariate analysis. Hoboken: John Wiley \& Sons, Inc.; 2012. p. 435-77.

34. Cattell RB. The scree test for the number of factors. Multivariate Behav Res. 1966;1:245-76.

35. Metzger BE, Gabbe SG, Persson B, Buchanan TA, Catalano PA, Damm P, et al. International association of diabetes and pregnancy study groups recommendations on the diagnosis and classification of hyperglycemia in pregnancy. Diabetes Care. 2010;33:676-82.

36. Xiang M, Konishi M, Hu H, Takahashi M, Fan W, Nishimaki M, et al. Reliability and validity of a Chinese-translated version of a pregnancy physical activity questionnaire. Matern Child Health J. 2016:20:1940-7.

37. Ainsworth BE, Haskell WL, Herrmann SD, Meckes N, Bassett DR Jr, TudorLocke C, et al. 2011 compendium of physical activities: a second update of codes and MET values. Med Sci Sport Exerc. 2011;43:1575-81.

38. Zhou B-F, Cooperative Meta-Analysis Group of the Working Group on Obesity in China. Predictive values of body mass index and waist circumference for risk factors of certain related diseases in Chinese adultsstudy on optimal cut-off points of body mass index and waist circumference in Chinese adults. Biomed Environ Sci. 2002;15:83-96.

39. Hu FB. Dietary pattern analysis: a new direction in nutritional epidemiology. Curr Opin Lipidol. 2002;13:3-9.

40. Ma G. Food, eating behavior, and culture in Chinese society. J Ethn Foods. 2015:2:195-9.

41. Du HY, Jiang $H, O K$, Chen $B, X u ~ \sqcup$, Liu SP, et al. Association of dietary pattern during pregnancy and gestational diabetes mellitus: a prospective cohort study in Northern China. Biomed Environ Sci 2017:30:887-897.

42. Li X, Jiang Y, Hu N, Li Y, Zhang M, Huang Z, et al. Prevalence and characteristic of overweight and obesity among adults in China, 2010. Chinese J Prev Med. 2012;46:683-6.

43. Gijsbers L, Ding EL, Malik VS, de Goede J, Geleijnse JM, Soedamah-Muthu SS. Consumption of dairy foods and diabetes incidence: a dose-response meta-analysis of observational studies. Am J Clin Nutr. 2016;103:1111-24.

44. Villegas R, Xiang YB, Elasy T, Li HL, Yang G, Cai H, et al. Fish, shellfish, and long-chain n-3 fatty acid consumption and risk of incident type 2 diabetes in middle-aged Chinese men and women. Am J Clin Nutr. 2011;94:543-51.

45. Kahn BB, Flier JS. Obesity and insulin resistance. J Clin Invest. 2000;106:473-81.

46. Polonsky KS, Given BD, Hirsch L, Shapiro ET, Tillil H, Beebe C, et al. Quantitative study of insulin secretion and clearance in normal and obese subjects. J Clin Invest. 1988:81:435-41.

47. Balistreri CR, Caruso C, Candore G. The role of adipose tissue and adipokines in obesity-related inflammatory diseases. Mediat Inflamm. 2010;2010:802078.

48. Walstra P, Jenness R. Dairy chemistry and physics. New York: John Wiley \& Sons; 1984.

49. Fox PF. Milk proteins: general and historical aspects. In: Fox PF, McSweeney $\mathrm{PLH}$, editors. Advanced dairy chemistry, volume 1: proteins. New York: Kluwer Academic/Plenum Publishers; 2003. p. 1-48.

50. Belobrajdic DP, McIntosh GH, Owens JA. A high-whey-protein diet reduces body weight gain and alters insulin sensitivity relative to red meat in wistar rats. J Nutr. 2004;134:1454-8.

51. Sousa GT, Lira FS, Rosa JC, de Oliveira EP, Oyama LM, Santos RV, et al. Dietary whey protein lessens several risk factors for metabolic diseases: a review. Lipids Heal Dis. 2012;11:67.

52. Wall R, Ross RP, Fitzgerald GF, Stanton C. Fatty acids from fish: the antiinflammatory potential of long-chain omega-3 fatty acids. Nutr Rev. 2010;68:280-9.

53. Sunwoo HH, Gujral N. Chemical composition of eggs and egg products. In: Cheung PCK, Mehta BM, editors. Handbook of food chemistry. Heidelberg: Springer; 2015. p. 331-63.

54. Blesso CN. Egg phospholipids and cardiovascular health. Nutrients. 2015;7: 2731-47.

55. Drew BG, Rye KA, Duffy SJ, Barter P, Kingwell BA. The emerging role of HDL in glucose metabolism. Nat Rev Endocrinol. 2012;8:237-45. 
56. Ciccone MM, Cortese F, Gesualdo M, Carbonara S, Zito A, Ricci G, et al. Dietary intake of carotenoids and their antioxidant and anti-inflammatory effects in cardiovascular care. Mediat Inflamm. 2013;2013:782137.

57. Jahandideh F, Chakrabarti S, Davidge ST, Wu J. Egg white hydrolysate shows insulin mimetic and sensitizing effects in 3T3-F442A pre-adipocytes PLoS One. 2017;12:e0185653.

58. Foster GD, Wyatt HR, Hill JO, McGuckin BG, Brill C, Mohammed BS, et al. A randomized trial of a low-carbohydrate diet for obesity. N Engl J Med. 2003; 348:2082-90.

59. de Luis DA, Izaola O, Aller R, de la Fuente B, Bachiller R, Romero E. Effects of a high-protein/low carbohydrate versus a standard hypocaloric diet on adipocytokine levels and insulin resistance in obese patients along 9 months. J Diabetes Complicat. 2015;29:950-4.

60. Zuniga YL, Rebello SA, Oi PL, Zheng H, Lee J, Tai ES, et al. Rice and noodle consumption is associated with insulin resistance and hyperglycaemia in an Asian population. Br J Nutr. 2014;111:1118-28.

61. Tapsell LC, Neale EP, Satija A, Hu FB. Foods, nutrients, and dietary patterns: interconnections and implications for dietary guidelines. Adv Nutr. 2016;7: 445-54.

62. Sempos $\mathrm{CT}$. Some limitations of semiquantitative food frequency questionnaires. Am J Epidemiol. 1992;135:1127-32.

63. Chen LW, Low YL, Fok D, Han WM, Chong YS, Gluckman P, et al. Dietary changes during pregnancy and the postpartum period in Singaporean Chinese, Malay and Indian women: the GUSTO birth cohort study. Public Health Nutr. 2014;17:1930-8.

Ready to submit your research? Choose BMC and benefit from:

- fast, convenient online submission

- thorough peer review by experienced researchers in your field

- rapid publication on acceptance

- support for research data, including large and complex data types

- gold Open Access which fosters wider collaboration and increased citations

- maximum visibility for your research: over $100 \mathrm{M}$ website views per year

At $\mathrm{BMC}$, research is always in progress.

Learn more biomedcentral.com/submissions 